\title{
Study on the mechanism of water inrush in the arid western mining area
}

\author{
Chao Zheng ${ }^{1, *}$, Lan $\mathrm{Yu}^{1}$, Jiangyi $\mathrm{He}^{1}$, Fengfeng Yang ${ }^{1}$, Jufeng Zhang ${ }^{1}$ \\ ${ }^{1}$ Longdong University,School of Energe Engineering,745000 Qingyang, China
}

\begin{abstract}
The analysis found that the coal mining process in the western mining area has the mining loss and disaster effect of the water-rich aquifer of the coal seam roof, which is mainly manifested by the overburden water in the roof. On this basis, the formation and development of the separation water of the roof is proposed, and the mechanism of the water inrush from the layer is revealed. It is found that there is hydrostatic pressure and hydrodynamic pressure in the separated water, under the combined action of bed separation water pressure, the mining-induced fracture and water-isolation layer tension fracture are connected, which causes water inrushing in the coal working face of the mine, and provides a theoretical guarantee for the large-scale development of coal resources in western mining areas.
\end{abstract}

As the world's largest coal producer and consumer, China has always been an inexhaustible motive force for China's rapid economic growth. As coal development shifts to the west, the ecological environment of the western mining area is fragile, water resources are scarce, and "coal-water" is counter-trending. The coal mining disturbance will inevitably lead to the redistribution of the stress field of the underground rock mass and the rupture damage of the rock mass, changing the circumference. The permeability of rock destroys the natural circulation of surface and groundwater systems, causing the loss of surface water and groundwater, leading to the deterioration of mine water inrush and ecological environment. The study found that the western mining area is mainly the mining loss and disaster effect of the water-rich aquifer in the coal seam roof. In recent years, there have been many roofs in the Binchang mining area, Linyou mining area and Yongning mining area of the Huangqi coal base in the Ordos Basin. The accident of water separation from the water layer poses a huge threat to the safe production and groundwater loss of the mine ${ }^{[1-2]}$. Therefore, the research on the mechanism of roof water inrush from the roof provides safety technology for the western mining area.

\section{The occurrence of aquifers in Ningzheng Mining Area}

Ningzheng mining area is located in the southeast of Qingyang city, Gansu province. The mining area is located in the southwestern margin of the Ordos basin. The administrative division is under the jurisdiction of Zhengning county and Ning county in Qingyang city, and is connected to the Binchang coalfield and the Xunyi coalfield in Shaanxi. According to the natural conditions in the area, the water-bearing and water-repellent layers in the mine field can be divided into five aquifers and three aquifers according to their water content, water type and hydraulic characteristics. The preliminary analysis of geological exploration suggests that the main aquifers that have an impact on mine mining are the third layer of the lower cretaceous Zhidan group, the fractured aquifer and the fourth layer of the coal seam roof of the middle Jurassic Zhiluo formation, Yan'an formation, The central sandstone composite confined aquifer .

The pores and fissure confined aquifers of the lower cretaceous Zhidan group. The aquifer has a thickness of 268.39 to $683.00 \mathrm{~m}$ and an average thickness of 421.12 $\mathrm{m}$. The aquifer is divided into upper and lower parts. The upper part is the pores of the Huanhe river and Huachi formation, and the fissure-bearing aquifer. The lower part is the pores of the Luohe and Yijun formations and the fractured aquifer. Luohe formation, Yijun formation pores, fissure confined aquifer, lithology mainly purple red, brown red medium coarse sandstone, good water content, thickness $256.86 \sim 508.13 \mathrm{~m}$, average thickness $392.06 \mathrm{~m}$. The northwest is thicker and thinner to the southeast. In the low-lying valleys, the boreholes of this group are often formed as self-flowing water, which should be medium-rich aquifers.

\section{Mechanism of occurrence of mine water inrush}

There are three basic conditions for the occurrence of overburden water in the mine. The first condition is the water source of the inrush water. The Cretaceous strata above the Jurassic coal-bearing strata in the western Ordos basin have a thicker layer and a better water-rich Luohe formation. The confined aquifer has the water source condition of the mine water inrush. Secondly, the

\footnotetext{
* Corresponding author: $513242367 @$ qq.com
} 
mining fissure generated by coal seam mining provides a channel for water inrush from the mine water inrush; the third is the strength of the inrush water, and the strong water infiltration into the separated space is called the sufficient condition of the mine water inrush. This paper focuses on the development of the water inrush and the mining fracture of the coal seam mining roof in the western mining area, as shown in Fig.1.

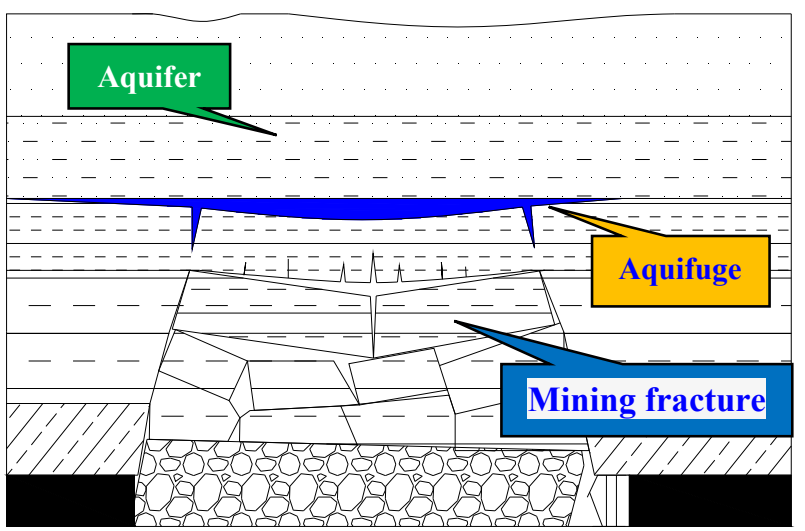

Fig.1 Mine water inrush structure

\section{Formation and development of the separation water from the roof}

\subsection{Formation conditions of overlying strata}

The coal-bearing strata are sedimentary rocks, and the layered sedimentary rocks can be regarded as composite beams that are stacked together by beams. After underground coal mining, the rock formation will undergo bending deformation. When the shear stress between the rock layers exceeds its shear strength, interlayer turbulence will occur. If the stiffness of each rock layer is different, the deflection deformation is not coordinated, and the rock layers are separated, resulting in separation. When the tensile stress acting on the rock body reaches its tensile strength, the rock mass breaks. If the upper rock layer breaks, the separation layer is closed; when the lower rock formation breaks, the separation layer continues to expand. The overburden is separated from the layer and the following basic conditions should be met, as shown in Fig.2.

\subsubsection{Rock formation conditions.}

The structural conditions of the strata between adjacent rock layers are hard and soft.

$$
f_{\text {上 }}>f_{\text {下 }}
$$

In the formula, $f_{\text {上 }}, f_{\text {下 }}$ is the rockwell hardness coefficient of the rock formation.

\subsubsection{Mechanical conditions.}

When the shear stress between the rock layers exceeds its shear strength, the rock formations are separated along the layer.

$$
\tau>c+\sigma \tan \varphi
$$

In the formula, $\sigma, \tau$ is vertical stress and shear stress on the rock stratum level; $c, \varphi$ rock layer level cohesion and internal friction angle.

\subsubsection{Vertical displacement conditions.}

When there is a separation between the rock layers, the vertical deflection of the upper formation is less than the vertical deflection of the lower formation, $W_{\text {上 }}<W_{\text {下 }}$.

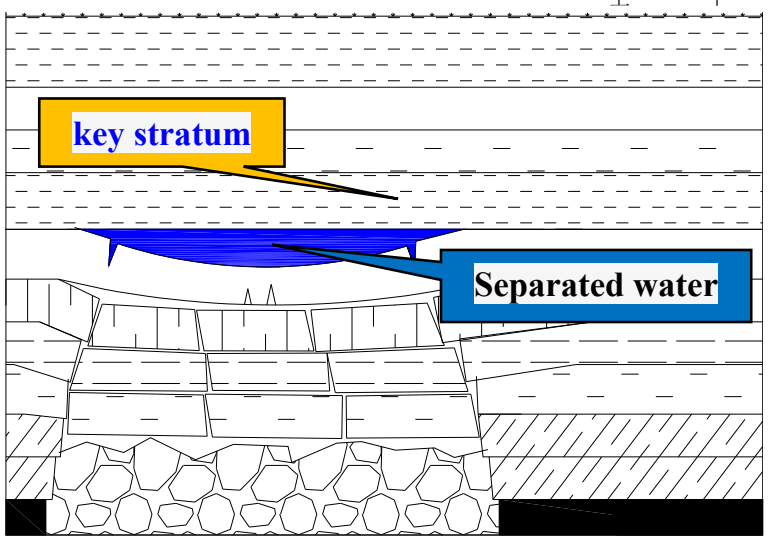

Fig.2 Developmental law of Separated water

\subsection{Dynamic evolution of separated water}

The formation of the separated water mainly depends on the size of the separation space, the duration of the separation layer, and the water-rich aquifer. For each delamination layer, there is a dynamic process from the beginning, development, stability to closure at the level. The greater the amount of delamination developed in the overburden after the coal seam is mined, the longer the duration, the longer the recharge time of the detachment of the surrounding aquifer, and the greater the amount of water in the detachment ${ }^{[3]}$.

The size of the separation space and the duration of the separation are mainly determined by the mining height and the swell of the direct roof. When the conditions are formed, the larger the working face width, the larger the pushing distance, the larger the coal thickness, and the larger the development space of the separation layer. The better the water content of the upper layer rock layer and the higher the water pressure, the greater the amount of water accumulated in the separation space.

\section{Development and influencing factors of mining fracture}

\section{1 mining cracks}

After coal mining, the stress in the overburden around the goaf is redistributed, and the overburden deforms, destroys, and collapses. In the vertical direction of the goaf, "three zones" and "four zones" are formed, of which the fall zone and the fracture zone forms a water- 
conducting fracture zone, which evolves into a water inrush channel. The "under three" believe that the development height of the water-conducting fracture zone is only related to the lithology and mining height of the overburden ${ }^{[4]}$. Field measurements show that the development of water-conducting fracture zone in fully mechanized caving mining is based on the "key layer" theory of the development of the jump ${ }^{[5-6]}$, the influencing factors include mining height, mining depth, coal seam dip, working face size and overburden structure characteristics. After gray correlation analysis, it is found that the mining thickness and the working face size have a great influence, and the coal seam dip angle has the least influence ${ }^{[7]}$.

\subsubsection{Mining thickness}

The thickness of mining reflects the size of the vertical direction of the mining space, and it has an influence on the stress redistribution, deformation and fracture range of the roof rock after mining. In the traditional empirical formula, it is the only influence parameter that predicts the height of the water guide. Under the premise that other mining conditions are the same or similar, the development height of overburden fractures in the thin coal seam mining or the first layer mining of thick coal seams is roughly linearly related to the mining thickness, but in the case of large mining height and fully mechanized top coal caving mining, It presents a fractional function growth relationship ${ }^{[8]}$.

\subsubsection{Working face size}

The size of the working face is mainly reflected in the inclined length of the working face and the advancement of the working face. The size of the working face mainly constrains the mining adequacy of the working face in two directions. If the full mining is achieved, the main key layer is broken, and in theory the fracture develops to the surface, but due to the mining height and mining design, most of the working faces cannot reach full mining. For the separation crack, the faster the working surface advances, the development of the separation crack - the closing time is fast, and the separation water is not easily formed. Therefore, the advancement speed of the working face, the inclined length of the working face, and the size of the goaf affect the water-conducting fracture zone under certain conditions, but the working face size plays a role under the condition that the overburden is not fully blasted ${ }^{[9]}$.

\subsubsection{Type of roof rock formation}

The roof rock stratum structure type and lithology are the basic indicators affecting the water-conducting fissure in the traditional calculation formula. The structural types of the roof rock mass of the coal seam are different, and the range of the roof rupture height after mining is also different. In order to avoid the use of uniaxial compressive strength to represent the strength of roof strata in traditional specifications and fully reflect the combined structure of soft and hard roof strata, a new parameter index is proposed, thai is the lithology ratio coefficient of hard rock. Practice shows that the roof rock mass is weak and broken, and its mining fracture height is relatively small; the hard and complete roof rock mass has a relatively large mining fracture height.

\subsection{Aquifuge tension fissure}

After coal seam mining, the deformation and failure process of overburden in the stope is gradually developed from bottom to top. Due to the swell of the rock mass, the degree of deformation and damage after the final stabilization gradually decreases from bottom to top. When bending occurs in any of the overburden layers in the overburden, the rock formation after bending deformation will be elongated compared to the horizontal state ${ }^{[10]}$, as shown in Fig.3. Once the tensile stress reaches the tensile strength of the rock, the rock layer will produce tensile cracks perpendicular to the layer. The tensile crack is located at the edge of the upper layer of the aquifer, and the lower surface of the aquifer is near the middle. The capacity will also be greatly reduced, and then the rock layer will further settle and bend, and the fracture surface will continue to develop until the entire thickness of the rock layer is penetrated to form a fracture ${ }^{[1-12]}$. The tensile cracks in the mining fracture and the aquifers penetrate each other under the action of the mining stress and the separated water pressure, which may cause a water seepage accident.

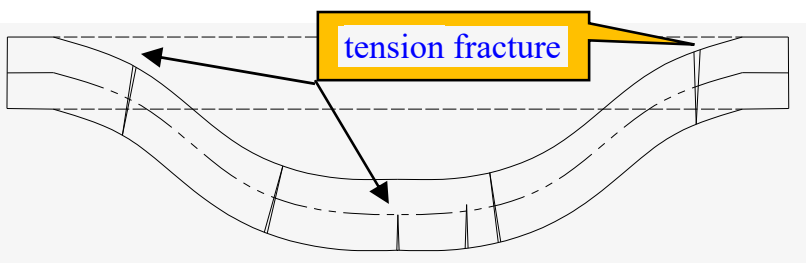

Figure. 3 tension fissure of aquifuge

\section{Mechanism of action of water inrush}

\subsection{Static pressure water}

As the work advances forward, the lithology is bent under the hard roof rock layer, and the lateral lateral fracture gradually develop, accompanied by the overburden and surrounding aquifers continuously replenishing the separated space; with the amount of separated water and overburden the deformation gradually increases, and the water level rises from the layer, and there is a certain hydrostatic pressure. The separated water will exert a certain load and hydrostatic pressure on the lower water-bearing rock formation ${ }^{[13]}$. Under the wedge or tension of the loading and hydrostatic pressure, the vertical fracture of the sub-level intact rock formation will lose its original barrier water. The thickness of the effective water-repellent layer in the complete rock layer is gradually reduced, and the load transfer of the lower-level separated water causes a constant load on the working face, increasing the load of 
the working face support, causing the outburst water and the pressure frame, and its main controlling factors. It is the hydrostatic pressure of the separated water and the thickness of the lower aquifer.

\subsection{Dynamic pressure water inrush}

The main cause of dynamic pressure water inrush is the impact dynamic load when the hard layer of the upper layer reaches the ultimate breaking distance fracture. The rock layer impact dynamic force squeezes the separated layer water, and the roof pressure and water pressure jointly produce dynamic pressure water inrush. The offwater hydrodynamic water has the characteristics of large instantaneous water volume and a large amount of gravel influx, and its impact dynamic force is strong. The strength of dynamic pressure and water inrush is mainly determined by its overlying strata and its physical and mechanical properties. When the upper layer of the separation layer is of great thickness, good integrity, high strength and large ultimate collapse distance, the impact dynamic load will also be extremely strong, and the corresponding power breakthrough zone will be larger, and the more likely it is to cause the hydraulic pressure to escape from the layer. Therefore, the key to prevent the dynamic pressure from the layer is to protect the fracture of the hard rock key strata ${ }^{[14]}$.

\section{Conclusion}

The ecological environment of the western mining areas represented by the Ningzheng mining area is fragile, especially the water resources in the Ordos basin in the west are extremely scarce.It is found that the water source of coal mining roof inrush in western mining area is the water generated by the separation layer under the roof aquifer of luohe formation, and the separation layer water changes dynamically with the advance of working face.The paper reveals the formation and mechanism of bed separation water, and puts forward that water inrush from bed separation water is the result of the joint action of water source and water channel.In addition to hydrostatic and dynamic water pressure effects on the waterproof layer, the presence of layer separation water will produce compound effects on the tensile fracture of the waterproof layer, leading to the connection of the mining fracture and tensile fracture, and causing the mine to burst water.

\section{Acknowledgement}

This work was financially supported by 2018 Gansu Provincial Safety Science and Technology Project [GAJ00017], 2018 Coal Industry Technology Project [MTKJ2018-280] and 2016 Longdong University Youth Science\&Technology Innovation Project [XYZK1611] fund.
1. Q.Lin,W.Qiao.Waterprevention and control technology of roof bed separation in Cuimu Mine.Coal ScienceandTechnology,44,129-134(2016)

2. J.F.Lou,G.Xu,Q.Lin.Research on roof disaster mechanism and prevention under soft waterenriched roof in Yonglong Coalfield.Coal Science and Technology, 46,10-18(2018)

3. J.M.Wang,D.H.Yu.Simulation of water hazards caused by burst of water cells formed.Chinese Journal of Geotechnical Engineering,32,231237(2010)

4. T.Q.Liu. Influence of mining activities on mine rock mass and control engineering.Journal of China Coal Society, 20,1-5(1995)

5. J.L.XU,W.B.ZHU,X.Z.WANG. New method to predict the height of fractured water-conducting zone by locationof key strata.Journal of China Coal Society,37,762-769(2012).

6. Y.TAN, ,D.M.YANG.Analysis on height of "two zones" under subcritical mining in shallow coal seam with hard roof.Journal of Mining \& Safety Engineering,34,845-851(2017)

7. W.B.GUO,G.Z.LOU. Definition and distinguishing method of critical mining degree of overburden failure.Journal of China Coal Society,44,755766(2019).

8. L.Q.SHI,H.Q.XIN,P.H.ZHAI.Calculatingthe height of water flowing fracture zone in deep mining.Journal of China University of Mining \& Technology,41,37-41(2012)

9. Y.LIU.Research on relationship between different width of working face and height of water-flowing fractured zone.safety in Coal Mines,41,13-17(2010)

10. Q.X.HUANG. Research on roof control of water conserva-tion mining in shallow seam. Journal of China Coal Society,42,50-55(2017)

11. Y.F.GAO,W.P.HUANG,G.L.LIU.The relationship between permeable fractured zone and rockstratum tensile deformation.Journal of Mining \&Safety Engineering, 29,301-306(2010)

12. Z.M.XU,Y.J.SUN,Q.H.DONG. Closing mechanism of mining-induced fracture in coal mine aquifuge and its application.Journal of Mining and Safety Engineering,29,613-618(2012)

13. W.Qiao,W.P.LI,X.Q.LI.Mechanism of hydrostatic water-inrush and countermeasures for water inrush in roof bed separationof a mining face. Journal of Mining and safety engineering,28,96-104(2011)

14. W.QIAO,W.P.LI,R.H.SUN. Formation mechanism of dynamic impact failure zone of super dynamic water inrush in coal mine. Chinese Journal of Geotechnical Engineering,33,1726-1733(2011)

\section{References}

